\title{
¿Seremos los verdugos de nuestros propios hijos? La comisión de vacunación en el Puerto de Veracruz, 1816-1817
}

\author{
Will We Be the Executioners \\ of our Own Children? \\ The Vaccination Commission \\ in the Port of Veracruz, 1816-1817
}

\author{
José Luis Galván Hernández \\ (D) https://orcid.org/0000-0002-6139-6569 \\ Instituto de Investigaciones Dr. José María Luis Mora, México \\ jgalvan@institutomora.edu.mx
}

Resumen: El objetivo de esta investigación es generar un primer acercamiento al funcionamiento y recepción de las campañas de vacunación establecidas en Nueva España a inicios del siglo xIx tras la expedición del médico Balmis, quien dio a conocer la vacuna de la viruela en los territorios de la monarquía católica. El mayor hallazgo de esta investigación reside en evidenciar la buena recepción que las campañas de vacunación tuvieron en el puerto de Veracruz durante el bienio 1816-1817, el trabajo de las autoridades locales para admi-

* Estudiante de la maestría en Historia Moderna y Contemporánea, Instituto de Investigaciones Dr. José María Luis Mora, México.

cómo citaR: Galván Hernández, J. L. (2020) ¿Seremos los verdugos de nuestros propios hijos? La comisión de vacunación en el Puerto de Veracruz, 1816-1817. Secuencia (108), e1761. DoI: https://doi. org/10.18234/secuencia.v0i108.1761

cC Esta obra está protegida bajo una Licencia Creative Commons Atribución-NoComercial 4.0 Internacional. 
nistrar el nuevo método de inmunización y su importancia en el contexto de la guerra de Independencia. En este sentido, la investigación abre el camino para que futuros trabajos se concentren en la organización y alcance territorial de estas campañas de vacunación durante el periodo de la guerra que dio fin al virreinato e identificar si tuvieron continuidad durante las primeras décadas del México independiente.

Palabras clave: viruela; vacuna; Nueva España; guerra de Independencia; medicina.

Abstract: The purpose of this research is to create an initial approach to the operation and reception of the vaccination campaigns established in New Spain at the beginning of the 19th century after the expedition by doctor Balmis, who introduced the smallpox vaccine into the territories of the catholic monarchy. The greatest finding of this research is the good reception vaccination campaigns enjoyed in the port of Veracruz during the biennium 1816-1817, the work of local authorities to administer the new immunization method and its importance in the context of the War of Independence. In this respect, the research paves the way for future studies to focus on the organization and territorial scope of these vaccination campaigns during the period of war that ended the viceroyalty and to determine whether they continued during the early decades of independent Mexico.

Key words: smallpox; vaccine; New Spain; war of Independence; medicine.

Recibido: 20 de junio de 2019 Aceptado: 06 de septiembre de 2019 Publicado: 21 de julio de 2020

$\mathrm{E}^{1}$ 16 de abril de 1813, Francisco Hernández, subdelegado del Tribunal Nacional del Protomedicato, recibió a un paciente en el Hospital Nacional de Veracruz. El enfermo presentaba costras además de algunas erupciones con pus que alertaron al facultativo, y al notar que el hombre no era vecino de la ciudad le preguntó de dónde venía. El enfermo comentó que era parte de la tripulación del barco Miño que días antes había llegado a Veracruz con tropas del ejército realista destinadas a la región de Perote. De inmediato el médico 
notificó a las autoridades de la Junta Superior de Sanidad de Veracruz para que tomaran cartas en el asunto. Al día siguiente se presentó en el hospital un segundo enfermo y fue el inicio de una gran preocupación entre las autoridades del Ayuntamiento; una vieja conocida volvía a presentarse en el territorio novohispano: la viruela. ${ }^{1}$

Aunque hay indicios de que la enfermedad existió desde la antigüedad en partes de África y Asia (Kotar y Gressler, 2013, pp. 3-8), ${ }^{2}$ en Europa se tienen registros claros de casos de viruela desde el siglo vi (Valdés Aguilar, 2010, pp. 27-28). Centurias más tarde las exploraciones europeas al continente americano cambiaron drásticamente el ecosistema, se introdujeron plantas y animales que eran desconocidos, las poblaciones se relacionaron de distintas maneras y las enfermedades europeas causaron estragos en aquellas sociedades que nunca habían tenido contacto con estos padecimientos (Crosby, 1991). Específicamente sobre el territorio que dio lugar al virreinato de Nueva España, la referencia más antigua sobre la viruela se encuentra en la crónica de Bernal Díaz del Castillo (1929, p. 224), quien refiere que el primer enfermo fue un esclavo "que fue causa de que se pegase e hinchase toda la tierra de ellas, de la cual hubo gran mortandad, que según decían los indios, jamás tal enfermedad tuvieron".

Los trabajos historiográficos sobre el impacto de la enfermedad, desde que se conoció en el territorio en el siglo xvi y hasta los años cincuenta del siglo $\mathrm{xx}$-cuando se erradicó-, son muy variados y es posible clasificarlos en dos grupos. En el primero se concentran aquellos trabajos que han estudiado las epidemias producidas antes del descubrimiento de la vacuna, ${ }^{3}$ mientras que en el segundo grupo se pueden agrupar estudios relativos a epidemias de viruela acaecidas tras la introducción de la vacuna, así como a las distintas campañas de vacunación que tuvieron por objetivo, durante gran parte del siglo XIX, contener el padecimiento y que tomaron una verdadera concien-

${ }^{1}$ Documentos relativos a epidemias de viruela. 1810-1816. Fondo Instituciones coloniales-historia. Vol. 530, exp. 2, fs. 4-5v. Archivo General de la Nación (en adelante AGN), México. Según los reportes del expediente, las autoridades veracruzanas consideraron que la epidemia de viruela que experimentó Xalapa en 1813 (y se extendió por gran parte del virreinato hasta 1816) se originó con el ingreso al territorio de esta tripulación infectada.

${ }^{2}$ Existen menciones de algo parecido a la viruela en el antiguo Egipto, así como en algunas dinastías chinas alrededor del siglo IV antes de nuestra era.

${ }^{3}$ Descubierta y utilizada a finales del siglo xviII por Edward Jenner en Inglaterra e introducida en Nueva España en 1804. Más adelante se abunda en cuestiones específicas de la enfermedad, lo que es la vacuna, cómo se descubrió y de qué manera llegó al virreinato. 
cia de erradicación hacia los años cuarenta y cincuenta del siglo xx. ${ }^{4}$ En este sentido, Cramaussel (2010) ofrece un trabajo excepcional para el estudio de la viruela en México debido a que la obra, en tres volúmenes, reúne una gran cantidad de estudios relativos a las epidemias suscitadas antes y después de la introducción de la vacuna.

Los trabajos relativos a los siglos XVI y XVII son muy pocos debido a la dificultad metodológica para identificar el impacto directo de la enfermedad en el descenso poblacional de aquellos años. No obstante, existen aportaciones clásicas respecto a los estragos causados por las primeras epidemias de viruela experimentadas en el territorio (Fournier, 1982, pp. 249-257) y estimaciones sobre el impacto demográfico de la enfermedad en los siglos referidos (Bustamante, 1982, pp. 67-93). En contraste, el mayor número de investigaciones en torno a la viruela en Nueva España se han concentrado en la centuria borbónica.

El siglo XVIII novohispano se ha estudiado con gran interés desde la perspectiva de un pujante crecimiento económico, resultado de una serie de medidas implementadas a lo largo de todo el siglo y que tradicionalmente se han conocido como Reformas Borbónicas. ${ }^{5}$ En ese sentido, estudios relativos al impacto de las enfermedades en la composición demográfica también han centrado su atención en dicho siglo, donde la presencia de viruela, tifo, sarampión, sífilis y tuberculosis fueron determinantes en la configuración poblacional por periodos y regiones específicas del virreinato. ${ }^{6}$ La razón de estas investigaciones reside en que durante el siglo referido se sucedieron varias epidemias de viruela que causaron grandes estragos entre la población, identificadas en los periodos 1762-1764; 1768-1770; 1778-1782, y 1795-1799 (Cramaussel, 2010). En gran medida estos trabajos se valen de la constancia do-

${ }^{4}$ Sobre estos estudios, el que reúne la mayor cantidad de trabajos relativos a la viruela desde una perspectiva de larga duración es Cramaussel (2010).

${ }^{5}$ Aunque este no es el espacio para debatir las implicaciones del término, coincido con los autores que han identificado distintos proyectos a lo largo de todo el siglo XVIII, que derivaron en la reconfiguración de ciertos aspectos en el gobierno económico-fiscal que impulsaron un paulatino crecimiento económico en el virreinato de Nueva España. Solamente como algunos ejemplos de estas investigaciones, véase Sánchez Santiró (2013); Kuethe y Andrien (2014); Torres Sánchez (2018, pp. 43-63); Pietschmann (2018, pp. 65-88).

${ }^{6}$ Sobre el tifo, el sarampión, la sífilis y la tuberculosis pueden consultarse distintos trabajos que estudian a estas enfermedades en perspectiva, destacando que la población novohispana las enfrentó, a veces, de manera simultánea y que esto incidió tanto en el comportamiento demográfico como en el diseño de estrategias para su control y prevención. Véase Florescano y Malvido (1982); Molina del Villar, Márquez Morfín y Pardo Hernández (2013); Torres Franco y Cramaussel (2017). 
cumental relativa a los estragos producidos por estos padecimientos, que han permitido reconstruir su impacto a nivel demográfico, social y económico.

El tránsito hacia el siglo XIX no fue ajeno a los padecimientos que de manera recurrente azotaron a la población novohispana. Sin embargo, el nuevo siglo introdujo un método que no solamente prevenía el contagio de viruela, sino que también servía como inmunizante permanente. A partir de ese momento las sociedades tuvieron una forma de protegerse contra la viruela; no obstante, el proceso de aceptación de la vacuna fue paulatino y la eventual erradicación de la enfermedad se produjo hasta mediados del siglo xx. ${ }^{7}$ En este sentido, los estudios relativos al comportamiento del padecimiento tras el uso extendido de la vacuna, los brotes epidémicos que no pudieron anticiparse pese al nuevo método de inmunización y el desarrollo de campañas que tuvieron por objetivo erradicar la enfermedad pueden reunirse en un segundo grupo, muy distinto a los trabajos referidos para los siglos XVI, XVII y XVIII. ${ }^{8}$

Empero, el tránsito de los viejos métodos para contener la viruela a la propagación de la vacuna ha recibido poca atención en la historiografía dedicada al estudio del padecimiento. Si bien existen abundantes trabajos sobre la expedición filantrópica del médico Francisco Xavier de Balmis, encargado por Carlos IV para llevar la vacuna al continente americano, ${ }^{9}$ carecemos de estudios específicos sobre las primeras comisiones de vacunación establecidas en el territorio. En gran medida la dificultad de estudiar el periodo que va de la entrada de la vacuna al virreinato en 1804 , hasta la independencia en 1821 , está acentuada por la dislocación que sufrió el territorio a causa de la guerra civil novohispana. ${ }^{10}$ Así, considero que para entender el grado de aceptación de la vacuna y la gestación de una incipiente consciencia de prevención en

${ }^{7}$ En este sentido, el trabajo de Agostoni (2016) presenta una investigación detallada respecto a los cambios en la lógica de las campañas de vacunación, cuyo principal aporte es entender que se pasó de una dinámica de contención de la enfermedad a mediados del siglo xix a una de erradicación mediante esquemas de colaboración internacional hacia mediados del siglo xx.

${ }^{8}$ Sobre este tipo de estudios, véanse Fernández del Castillo (1982, pp. 539-545); Dimas (2010, pp. 51-60); Carrillo (2010, p. 91) y Agostoni (2016).

${ }_{9}$ Como un ejemplo de la gran cantidad de trabajos relativos a Balmis, véanse Fernández del Castillo (1982, pp. 329-337); Veiga de Cabo, Fuente Díez y Martín Rodero (2007, pp. 71-84); Tuells (2012, pp. 372-375); Pardo Hernández (2013, pp. 451-462).

${ }^{10}$ Investigaciones sobre la guerra civil novohispana coinciden con la idea de dislocación territorial producto de la ruptura de comunicaciones y el enfrentamiento directo entre la insurgencia y el ejército virreinal. Véanse Jáuregui Frías (1999); Van Young (2006); Ortiz Escamilla (2014); Sánchez Santiró (2016). Respecto a estudios de enfermedades durante el periodo de la guerra destaca el trabajo de Sánchez Uriarte (2013), quien estudió la epidemia de fiebres miste- 
la otrora sociedad novohispana, es necesario reforzar nuestro conocimiento sobre dicho periodo.

En consecuencia, las preguntas que rigen esta investigación son las siguientes: ¿de qué manera se aplicó la vacuna tras su llegada al virreinato?, ¿cómo se convocaba a la población para que asistiera a vacunarse?, ¿cuál fue el grado de efectividad de la vacuna?, ¿cómo se resguardaba y transportaba? Para resolver estas interrogantes se ha seleccionado un periodo concreto de aplicación de la vacuna en Veracruz (1816-1817). Si bien el periodo referido se sitúa cuando la insurgencia ya no era considerada una amenaza, permite vislumbrar las consecuencias de la guerra y da cuenta de la manera en que las autoridades virreinales se organizaron para establecer una comisión permanente de vacunación con miras a prevenir una epidemia como la ocurrida en 1813.

La investigación se presenta en cuatro secciones: al inicio una sucinta descripción sobre lo que fue la viruela, las formas de contagio y los métodos de prevención que existían antes de la vacuna. La segunda sección se concentra en el descubrimiento de la vacuna por el inglés Edward Jenner, la introducción del nuevo método preventivo en Nueva España, como resultado de la expedición del médico Francisco Xavier de Balmis, y los reglamentos emitidos para establecer comisiones de aplicación en el territorio.

La tercera sección abunda en el estudio de caso: la manera en que la comisión de vacunación operó en el puerto de Veracruz en los años 1816 y 1817; para ello se analizan las actas de vacunación emitidas por las autoridades de la comisión. ${ }^{11}$ A partir de estas actas se ha identificado la cantidad total de vacunados en el periodo referido, la manera en que se aplicó la vacuna, los lugares donde se vacunaba y los rangos de edad de los inmunizados. Para un tratamiento adecuado de la información se han generado dos categorías para reunir a los vacunados: de cero a doce meses y de doce meses en adelante. Esta división responde a que, según Harrison (2002, p. 1310), antes de los doce meses se considera que el sistema inmunológico no está del todo listo para adecuarse

riosas -tifo- en 1813, sus implicaciones entre los bandos beligerantes, así como la difusión de la epidemia como resultado del desplazamiento poblacional como resultado del conflicto.

${ }^{11}$ Dichas actas permiten estudiar los años referidos, sin embargo, aportan indicios de que la campaña inició desde el año 1815 aunque, lamentablemente, no se ha conseguido la totalidad de dichos registros. Las actas referidas pueden consultarse en los volúmenes siguientes: Documentos relativos a epidemias de la viruela. 1810-1816. Fondo Instituciones coloniales-historia. Vol. 530; y Documentos relativos a epidemias de la viruela. 1816-1817. Fondo Real Hacienda-epidemias. Vol. 14, ambos en AGN, México. 
por completo a la vacuna. Sin embargo, en el periodo estudiado los desarrollos médicos ignoraban esta condición y la edad resultaba indiferente en la aplicación de la vacuna. Como se verá, la mayor cantidad de vacunados se situó en la primera categoría (de cero a doce meses) y esto es un reflejo de la percepción que se tenía sobre la nueva medida preventiva. Además, para ejemplificar el impacto de la campaña, esta sección también incluye un plano de la ciudad de Veracruz en el que se resaltan los lugares en que se aplicaron las vacunas.

En la cuarta sección se exponen los resultados del estudio de caso, algunas consideraciones sobre el tema presentado y se mencionan vetas de exploración para futuras investigaciones que aporten más detalles sobre la conformación de una conciencia preventiva a inicios del siglo XIX, así como nuevos elementos para comprender el proceso de profesionalización de la medicina en México desde sus primeros años independientes.

\section{LA ENFERMEDAD Y SU PREVENCIÓN ANTES DE LA VACUNA}

La viruela que azotó a la humanidad desde la antigüedad y hasta finales de los años setenta del siglo $\mathrm{xx}$ fue una enfermedad que únicamente afectaba a los humanos (Valdés Aguilar, 2010, p. 28). Era causada por un virus llamado variola que pertenece a la familia de los poxvirus del género orthopoxvirus. Esto quiere decir que existen otros tipos de virus de viruela que afectan a ciertos animales como el mono, el perro, el conejo y la vaca, pero que no infectan a los humanos de la misma forma que la viruela del virus variola. Es importante mencionar que el organismo que se infecta de viruela puede recuperarse y desarrollar inmunidad permanente, mas no absoluta (Valdés Aguilar, 2010, p. 30)..$^{12}$

El epidemiólogo Rafael Valdés Aguilar (2010) menciona que cuando una persona contrae el virus, la enfermedad se desarrolla en cuatro periodos:

1) Periodo de incubación: de siete a 17 días en los cuales la persona contagiada no presenta síntoma alguno y el virus no se ha desarrollado por

${ }^{12}$ Inmunidad permanente significa que la persona que haya sobrevivido a la enfermedad no puede contagiarse nuevamente. Sin embargo, en casos raros se presentaron pacientes con un segundo contagio, de ahí que se considere que no es una inmunidad absoluta, caso similar al de los pacientes que han padecido varicela en algún momento de su vida y que ante un mal funcionamiento del sistema inmunológico pueden presentar un segundo contagio. 
completo, situación que hace que en esta fase el portador no sea contagioso para otros.

2) Periodo prodrómico o sintomático inicial: de dos a cuatro días en los que aparecen los primeros síntomas que consisten en escalofríos, fiebre, dolores musculares, náuseas, vómito, diarrea y delirio. Estos síntomas se acompañan de una erupción rosada, distinta a las póstulas que surgen en la siguiente fase. Del tercero al cuarto día estos síntomas se alivian y en esta fase es poco probable que el enfermo sea contagioso.

3) Periodo eruptivo o de contagio: en esta fase surgen erupciones en la lengua y la boca como manchas rojas que se transforman en póstulas que revientan y diseminan el virus en boca y garganta. A la par surgen erupciones en la piel, primero en la cara, que se extienden por brazos, piernas, pies y posteriormente en el resto del cuerpo. Al tercer día del surgimiento las erupciones se convierten en abultamientos. Al cuarto día se llenan de un líquido espeso (se convierten en póstulas) y presentan un hundimiento en el centro. En este periodo regresa una fiebre elevada y eventualmente las póstulas se secan para formar costras que causan molestias al enfermo.

4) Periodo de resolución: después de tres semanas de iniciada la erupción las costras que se han secado se desprenden del cuerpo, aunque se presenta un alivio general la persona sigue siendo contagiosa hasta que se desprende la última costra.

Superado el último periodo la persona recuperada presenta inmunidad durante el resto de su vida. Aunque la enfermedad variaba de persona a persona, los más vulnerables y propensos a morir en el desarrollo fueron los infantes y los ancianos. Además, Harrison (2002, p. 1316) señala que la media estimada de mortalidad que presentó la enfermedad se colocó en $30 \%$. Un aspecto importante es que la enfermedad no tenía cura, únicamente había remedios para atenuar las molestias del enfermo, esperar a que su cuerpo respondiera favorablemente y se recuperara del virus. Sin embargo, hasta antes del descubrimiento de la vacuna existía una forma de prevenir el desarrollo pleno de la enfermedad y conseguir la inmunidad que protegiera de futuros contagios. El remedio en cuestión se conoció y realizó de distintas maneras, pero la más extendida de ellas se llamó inoculación.

La inoculación fue un método que consistía en diseminar el virus debilitado entre personas sanas para que desarrollaran inmunidad y no enfermaran ante el surgimiento de algún brote de viruela. El origen de esta técnica es incierto y posiblemente se conoció en distintas partes del mundo durante 
diversos momentos; sin embargo, se reconoce que la técnica llegó a la medicina europea en 1717 a través de Lady Montagu (esposa de Wortley Montagu, embajador inglés en Constantinopla), debido a que durante su estancia en el imperio Otomano decidió inocular a su hijo y a su regreso a Inglaterra compartió el método con médicos de la Corte (Williamson 2007, p. 5). Aunque en la época existían distintas explicaciones para sustentar la efectividad del método, simplemente se trataba de un contagio premeditado con un virus debilitado extraído de algún enfermo. La obtención del virus se hacía por medio de las pústulas; se recolectaba el líquido que contenía el virus y mediante incisiones en los brazos de personas sanas se les diseminaba la enfermedad, que desarrollaban en días posteriores, aunque con menor intensidad. De esta forma, la inoculación permitía contagiarse de viruela con menor riesgo de muerte y desarrollar la inmunidad que protegiera de por vida a la persona. ${ }^{13}$

La inoculación fue ampliamente recibida por la medicina europea del siglo XVIII y se utilizó para contener epidemias de viruela en determinados momentos (Espinoza Cortés y Miranda Ocampo, 2010, pp. 71-92; Trejo Moreno, 2016). Es necesario aclarar que no se trató de un método exclusivo ya que existían otros para lidiar con los contagiados, desde el uso de "polvos" para atenuar los síntomas, sangrías para nivelar los humores del cuerpo, inhalación y enjuagues con mercurio, hasta cuarentena con el objetivo de evitar contagios masivos en los poblados (Gil, 1784, pp. 45-55). A estos métodos se sumaron instrucciones específicas para el tratamiento de los enfermos, entre ellas destacan el uso de batas de lienzo, evitar contacto con el paciente, así como con los utensilios con los que haya tenido contacto, tener cuidado de limpiar las costras que fuera desprendiendo y limpiar exhaustivamente los lugares en los que el enfermo hubiera estado, para ello se utilizaba agua, vinagre y en algunos casos se quemaban ciertas pertenencias (Gil, 1784, pp. 62-66). De esta forma, para finales del siglo xviII se tenía certeza en la manera en que podía transmitirse la enfermedad, los riesgos de no controlar un brote, así como un método que permitía anticiparse al contagio; sin embargo, la inoculación resultaba peligrosa porque podía ser el origen de una epidemia o, en algunos casos, ciertos inoculados presentaban síntomas incluso más fuertes que el enfermo original (Moreau de la Sarthe, 1803, pp. X-XI).

${ }^{13}$ Si bien el método generó aceptación y rechazo es incuestionable que, en tratados médicos de la época, así como en posteriores, se hace referencia a la influencia de Lady Montagu en la introducción del método de inoculación entre las prácticas médicas europeas. 


\section{LA VACUNA. DE EDWARD JENNER A LAS COMISIONES EN NUEVA ESPAÑA}

En 1798 el médico inglés Edward Jenner publicó una serie de observaciones y experimentos en torno a una enfermedad bovina (cowpox), sus efectos en humanos y correlación con la viruela. En este trabajo Jenner (1798) explicaba que había una relación entre la enfermedad que desarrollaban las vacas y las personas encargadas de ordeñarlas, quienes presentaban algunas pústulas y ciertos malestares mínimos que con el paso de unos días desaparecían. Lo más interesante de las observaciones de Jenner es que las personas que desarrollaban esta enfermedad se volvían inmunes a la viruela humana, por lo que el médico inglés buscó la manera de aprovechar este descubrimiento y, tras varios intentos, logró establecer un procedimiento para ello.

El procedimiento utilizado fue la extracción del líquido de las pústulas de las vacas y hacer una inoculación en humanos para que desarrollaran inmunidad a la viruela. Los primeros experimentos de este método resultaron favorables, incluso se descubrió que era posible inocular a más personas a partir de un primer inoculado. La manera en que Jenner (1799) probó los resultados de este procedimiento fue a través de posteriores inoculaciones del virus humano a quienes previamente habían sido inoculados con el virus vacuno, en todos los casos pudo corroborar la inmunidad. El nombre que dio a su procedimiento fue Variolæ Vaccinæ (Vacuna de la Viruela) y a lo largo de sus trabajos publicados explicó la manera de obtener la vacuna, aplicarla y mantenerla de persona a persona para no tener que recurrir nuevamente al virus bovino. De manera prácticamente inmediata los trabajos de Jenner fueron consultados y traducidos por el médico francés Jacques-Louis Moreau de la Sarthe, esto provocó que la vacuna se utilizara en algunas partes de Francia y las publicaciones se dispersaran por el resto del continente. Como resultado, en la monarquía católica el médico Francisco Xavier de Balmis consultó la traducción francesa y notó el potencial del descubrimiento, por lo que solicitó permiso para realizar una traducción al español y posteriormente pidió apoyo para poner en marcha la extracción y aplicación de la vacuna. La propuesta de establecer una expedición que llevara la vacuna a todo el reino fue iniciativa del propio Balmis, quien recibió apoyo de Carlos IV (Ramírez Martín, 2002). El objetivo de la expedición era frenar una epidemia que había surgido en Nueva Granada, diseminar la vacuna en América y llevarla hasta Filipinas. Para cumplir esta misión se reclutaron varios niños para que conservaran el 
fluido vacuno mediante la vacunación de uno en uno, esto con el objetivo de mantener viva la vacuna debido a lo difícil que podía resultar conseguirla sin las condiciones apropiadas.

Como resultado de la expedición de Balmis, la vacuna llegó a Nueva España en 1804 y de inmediato se habilitaron casas como centros de vacunación, se enseñó a los médicos locales la manera de obtener, conservar y transmitir la vacuna, así como su aplicación, especialmente recomendada entre los niños debido a los riesgos que implicaba que contrajeran viruela (Pardo Hernández, 2013, p. 456). Años más tarde el rey emitió distintos reglamentos para seguir fomentando la aplicación de la vacuna en Nueva España, en estos reglamentos se especificaban algunas de las disposiciones que la primera expedición había dejado, pero también reglamentaban a las autoridades encargadas de la aplicación, los procedimientos para hacerlo y algunas exigencias para constatar el total de personas vacunadas.

Además, las autoridades se preocuparon por fomentar que los habitantes de las ciudades llevaran a sus hijos a vacunar; para ello utilizaron "avisos" que se publicaban y leían en las calles con la intención de que los habitantes, especialmente las mujeres, se enteraran de los beneficios de la vacuna. Algunos de estos bandos enfatizaban los beneficios del descubrimiento, la necesidad de vacunar a los niños (aunque también invitaban al grueso de la población) y en gran medida apelaban a que en caso de no atender las recomendaciones se ponía en riesgo la vida de los infantes. Lo más destacado de estos avisos es que aportan información sobre la vacuna: la aplicación era gratuita; los gastos eran absorbidos, en su totalidad, por el Ayuntamiento; los médicos de la localidad eran los encargados de su aplicación y los días de vacunación se daban a conocer oportunamente. ${ }^{14}$

¿La introducción de la vacuna generó que el viejo método de inoculación dejara de emplearse para prevenir contagios? Lo más probable es que no, más bien, es altamente probable que ambos métodos convivieran aunque el discurso expuesto en los documentos emitidos tras la Expedición Filantrópica permite suponer que se optó por priorizar la administración de vacunas sobre la inoculación..$^{15}$ Resulta de suma importancia entender la lógica de la enfer-

${ }^{14}$ Bando sobre la aplicación de la vacuna, 12 de diciembre 1810. Fondo instituciones coloniales-historia. Vol. 530, exp. 4, f. 12. AGN, México.

${ }^{15}$ A propósito, es necesario mencionar que incluso Balmis llegó a usar y defender el uso de ambos métodos, pese a que prefería conservar el fluido vacuno. Además, el médico español estaba convencido que aplicar la vacuna era más seguro que la inoculación y aportaba mayores 
medad en el territorio ya que, de hecho, el virreinato recurrentemente padeció de epidemias de viruela: 1768-1770; 1778-1782; 1795-1799; 1813-1816 (Cramaussel, 2010; Méndez Main, 2010). Además, estas epidemias no llegaban solas y es que se combinaban con otros padecimientos como el tifo y el sarampión (Torres Franco y Cramaussel, 2017), lo que causaba estragos en la población.

\section{LA COMISIÓN DE VACUNACIÓN EN VERACRUZ, 1816-1817}

Tras la captura del líder insurgente, José María Morelos, a finales de 1815, las autoridades virreinales fragmentaron al movimiento y se concentraron en resistir los embates de algunas guerrillas dispersas por el territorio. Esta situación propició el restablecimiento de las vías de comunicación en el virreinato, la reconstrucción de algunas ciudades capturadas por los insurgentes y una paulatina recuperación económica (Sánchez Santiró, 2016, p. 267). Como resultado, regiones que por años tuvieron que valerse por sí mismas para obtener recursos y aprobar providencias extraordinarias para mantenerse fieles al régimen reestablecieron el contacto con la sede del gobierno virreinal en la ciudad de México (Galván Hernández, 2017, pp. 70-80). Entre los asuntos que llegaron a las autoridades de la Audiencia de México se encontraban las actas de vacunación de algunas de las comisiones establecidas en ciertas intendencias.

Las actas referidas fueron solicitadas desde inicios de 1815 por el fiscal de Real Hacienda, encargado de la fiscalía de lo civil de la Audiencia de México, como parte de las reglamentaciones que se tenían en torno a las comisiones de vacunación instaladas en el reino. Estas actas dan cuenta de la cantidad de vacunados en algunas ciudades del reino: Puebla, Mérida, Acayucan, Campeche, Antequera, Veracruz y en las Provincias de Oriente. ${ }^{16}$ Sin embargo, la comisión de vacunación de Veracruz fue la que envió la mayor cantidad de información, por lo que se ha podido reconstruir con detalle el funcionamiento

beneficios. Véanse los trabajos que han profundizado en la expedición: Fernández del Castillo (1982); Ramírez Martín (2002); Veiga de Cabo, Fuente Díez y M. Rodero (2007); Pardo Hernández (2013). Además, algunas de las indicaciones que Balmis dejó en los ayuntamientos novohispanos: Compilación de documentos relativos a la viruela, 1815-1817. Fondo Instituciones coloniales-historia. Vol. 530, exp. 1, fs. 1-7v. AGN, México.

${ }^{16}$ Compilación de documentos relativos a la viruela, 1815-1817. Fondo Instituciones coloniales-historia. Vol. 530, exp. 1. AGN, México. 
de esta comisión, algo que resulta fundamental para entender su impacto y aceptación entre la población de la capital de aquella intendencia.

El reglamento para el establecimiento de comisiones de vacunación en Nueva España determinaba que los intendentes de cada provincia quedaban encargados de estimular el funcionamiento de las comisiones, convocar a la población para que se vacunara y llevar un registro específico de los vacunados, efectividad y casos en los que no surtiera efecto. ${ }^{17}$ Además, se establecía que la vacuna debía conservarse en recipientes de vidrio, lejos de la luz solar y transmitirse, preferentemente, de individuo a individuo para evitar que se perdiera. Otro aspecto fundamental es que el reglamento contemplaba la diseminación de la vacuna a través de la convocatoria de curanderos de los poblados alejados de las capitales de las intendencias, para ello los curanderos debían llegar con uno o más niños para que fueran inoculados y pudieran portar la vacuna hasta su poblado de origen. Además, estos curanderos eran instruidos en los métodos de aplicación y formas de detectar la viruela bovina para una posible obtención de la vacuna de manera natural. ${ }^{18}$

La comisión de vacunación que se estudia a continuación se planificó como respuesta a un contexto sumamente adverso en el virreinato. En 1813 se afrontaba el periodo más duro de la guerra civil novohispana, pero ante los avances en el frente ibérico las autoridades metropolitanas lograron enviar tropas realistas para apoyar la lucha del gobierno virreinal contra los insurgentes comandados por Morelos (Ortiz, 2017, pp. 148-162). En la introducción de esta investigación se refiere que dichos soldados realistas introdujeron, nuevamente, una epidemia de viruela en el territorio cuyo mayor punto de contagio se produjo en 1814, y durante dos años se propagó por gran parte del territorio (Méndez Main, 2010, pp. 83-85). Una de las consecuencias directas de esta nueva epidemia fue reactivar las comisiones de vacunación que se habían diseñado desde la Expedición Filantrópica de Balmis y cuya reglamentación se emitió en $1810{ }^{19}$

En el caso concreto de la comisión de Veracruz, la convocatoria de vacunación se hacía por medio de bandos colocados en las calles en las que se establecerían los lugares de vacunación. El fluido se obtenía de algún vacuna-

${ }_{17}$ Compilación de documentos relativos a la viruela, 1815-1817. Fondo Instituciones coloniales-historia. Vol. 530, exp. 1, f. 1. AGN, México.

${ }^{18}$ Compilación de documentos relativos a la viruela, 1815-1817. Fondo Instituciones coloniales-historia. Vol. 530, exp. 1, f. 3. AGN, México.

${ }_{19}$ Bando sobre la aplicación de la vacuna, 12 de diciembre de 1810. Fondo Instituciones coloniales-historia. Vol. 530, exp. 4, f. 12. AGN, México. 
do previo que para el día de la vacunación ya hubiera presentado la reacción característica del procedimiento; con dicho fluido se vacunaba a quienes llegaban al lugar asignado para tal fin. Posteriormente, con el objetivo de atraer a nuevas personas, se seleccionaba otra ubicación para la casa o tienda de vacunación, se esperaban algunos días para que los nuevos vacunados, al igual que sus predecesores, presentaran la reacción característica de la vacuna y de ahí se seleccionaba alguno como fuente del nuevo fluido. ${ }^{20}$

Este procedimiento se siguió de manera puntual durante el bienio 18161817, vacunando, en promedio, cada seis días en distintas partes de la ciudad. Como resultado, desde que se estableció la comisión permanente en 1816 y hasta 1817 se realizaron 350 vacunaciones en 69 partes de la ciudad, lo que indica que algunas locaciones se repitieron en más de una ocasión. ${ }^{21} \mathrm{~A}$ continuación, se presenta el mapa 1 de Veracruz del año 1800 en el que se contempla un plan de crecimiento de ampliación de dicho año. Para efectos prácticos, el mapa ejemplifica lo que debió ser el Puerto de Veracruz en los años que se estudian, además, se han señalado los lugares que a partir de la documentación se sabe que sirvieron como punto de vacunación durante el periodo de estudio. El mapa permite observar que la mayor parte de las vacunaciones se realizaron en el centro y sur de la ciudad, muy pocas en la zona extramuros y el resto en la parte norte. La razón de esta distribución posiblemente tiene que ver con las particularidades de la vida urbana ya que, si se observa la simbología del plano, las zonas de afluencia: comercios, tribunales, aduana, parroquias y plazas se encuentran en donde hubo una mayor concentración de puntos de vacunación.

En el bienio 1816-1817 se vacunaron 983 individuos, por lo que para tener un manejo adecuado de la información se han generado dos categorías. La primera engloba a los individuos de cero a doce meses de vida, mientras que la segunda reúne a aquellos de doce meses en adelante. La razón de esta división se fundamenta en que los avisos que invitaban a vacunar a la población hacían especial énfasis en presentar a los recién nacidos. ${ }^{22}$ En 1816 se

${ }^{20}$ Compilación de documentos relativos a la viruela, 1815-1817. Fondo Instituciones coloniales-historia. Vol. 530, exps. 5, 6, 7, 8, 9 y 10; Compilación de documentos relativos a epidemias, 1815-1818. Fondo Real Hacienda-epidemias. Vol. 14, ambos en AGn, México.

${ }^{21}$ Para efectos de este análisis me refiero a comisión permanente a partir de lo registrado en la documentación. Sin embargo, estos mismos documentos mencionan que en años previos hubo comisiones de vacunación que funcionaron de manera esporádica.

${ }^{22}$ Compilación de documentos relativos a la viruela, 1815-1817. Fondo Instituciones coloniales-historia. Vol. 530, exp. 4, f. 12. AGN, México. 


\section{Mapa 1. Comisiones de vacunación} en Nueva Veracruz, 1816-1817

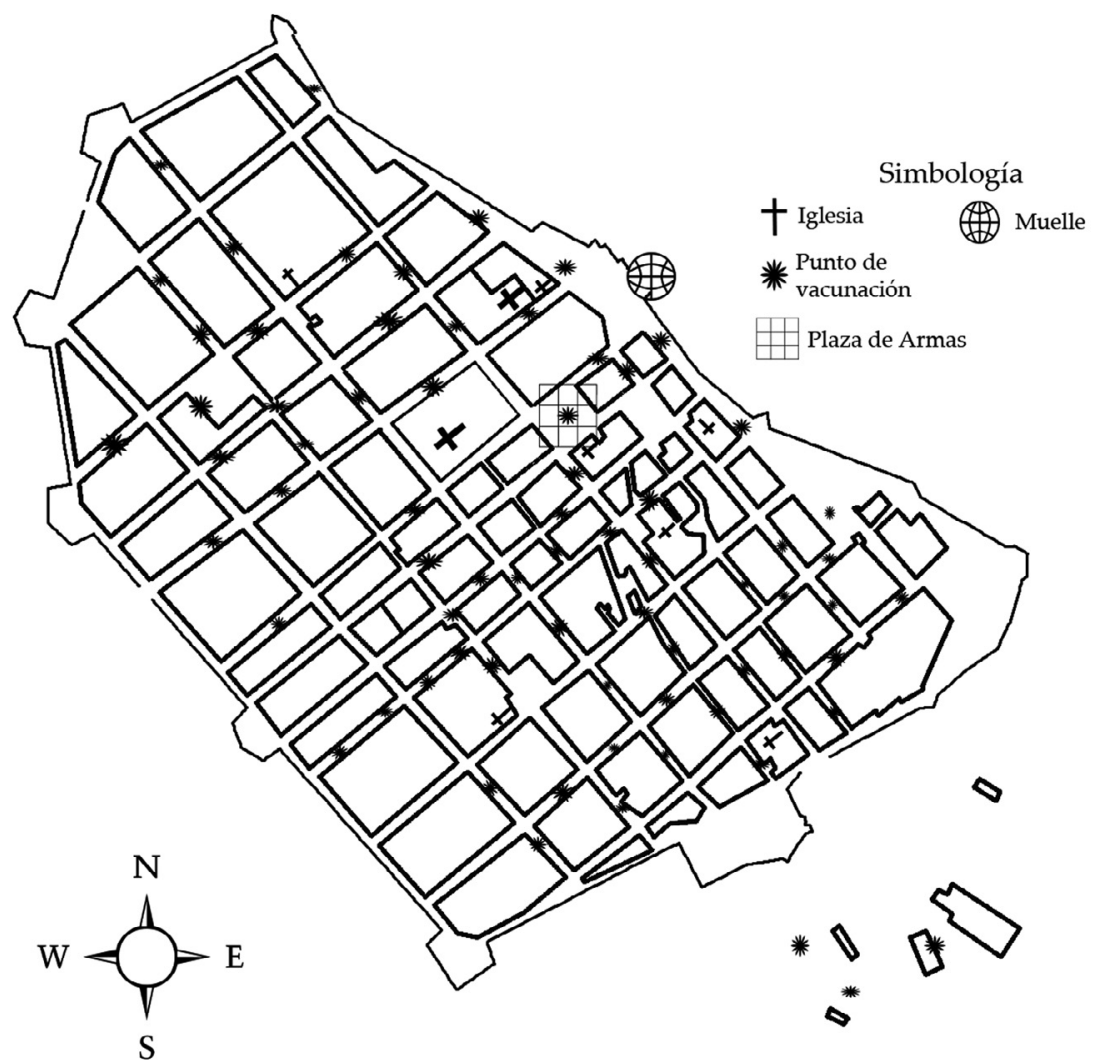

Fuente: elaboración propia a partir de fondo Instituciones coloniales-historia. Vol. 520, exp. 4; fondo Real Hacienda-epidemias. Vol. 14, ambos en AGN, México.

vacunó a un total de 550 individuos, de los cuales 369 fueron menores de doce meses y los 181 restantes mayores a un año (véase gráfica 1).

Si la cantidad de vacunados en 1816 se desglosa por mes se obtiene que en promedio se vacunaron 45.83 individuos. De esta forma, es posible estimar que las campañas presentaron una buena recepción entre la población de la ciudad (véase gráfica 2). En gran medida esta suposición se puede hacer por- 


\section{Grafica 1. Vacunados en 1816, agrupados por rango de edad}

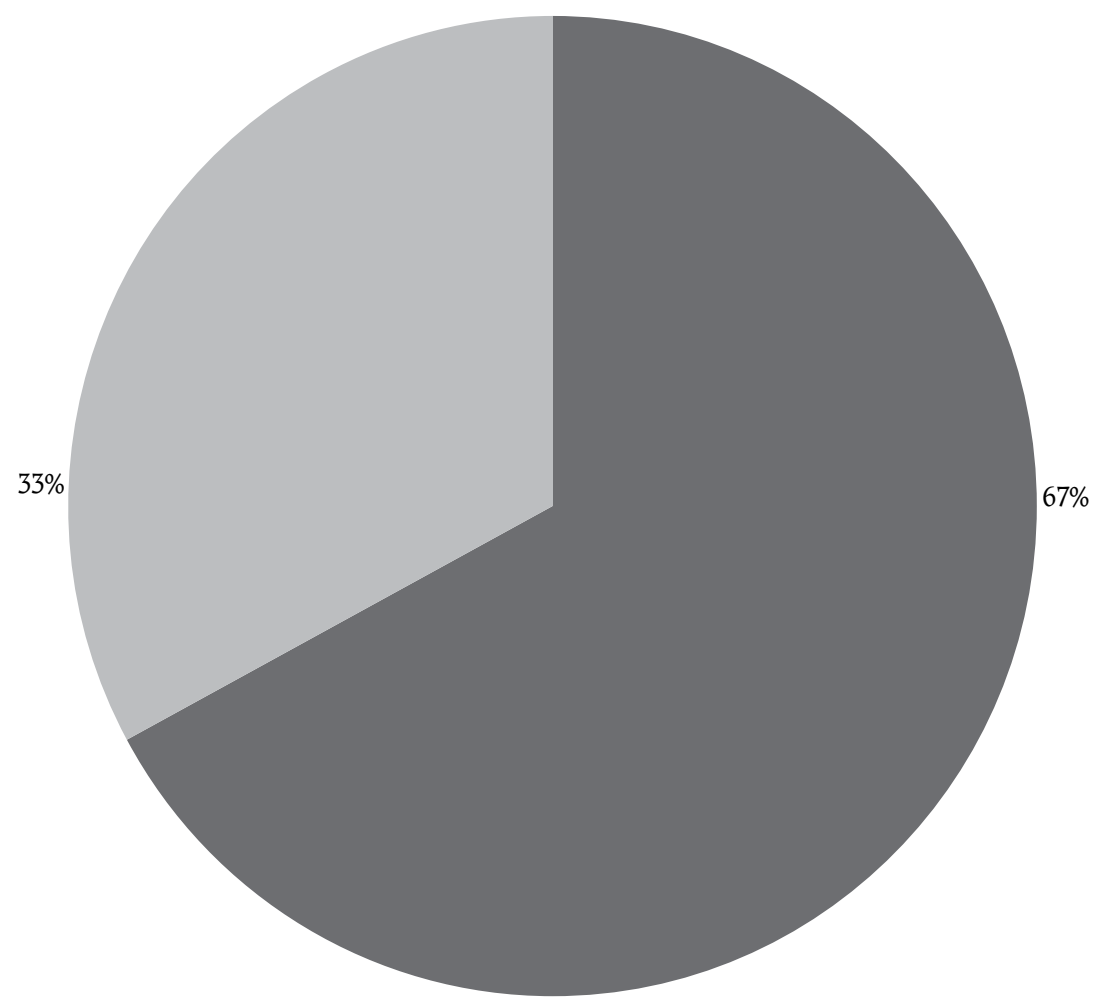

Total de vacunados hasta 12 meses

Total devacunados más de 12 meses

Fuente: elaboración propia a partir de Compilación de documentos relativos a la viruela, 1815-1817. Fondo Instituciones coloniales-historia. Vol. 530; y Compilación de documentos relativos a epidemias, 1815-1818. Fondo Real Hacienda-epidemias. Vol. 14, ambos en AGN, México.

que las autoridades encargadas de organizar las campañas tenían registros de los nacimientos mensuales, esto permitía que dieran seguimiento y vacunación oportuna a los neonatos. ${ }^{23}$ Sin embargo, la documentación no precisa de

${ }^{23}$ A partir de los registros encontrados en la documentación de las campañas de vacunación, se ha estimado que el promedio de nacimientos por mes era de 20 individuos. Tomando 


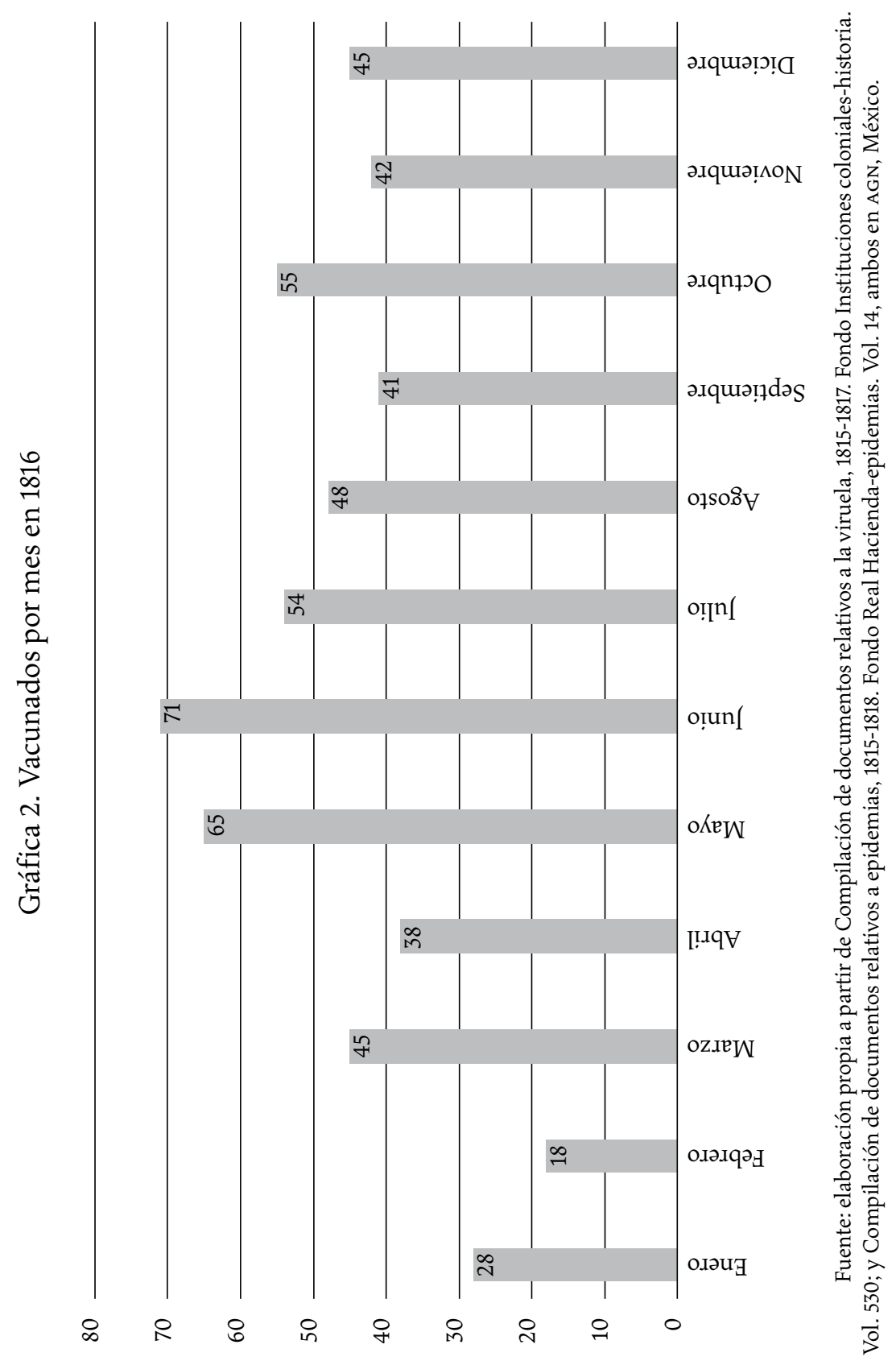


qué manera se garantizaba que los nacidos registrados fueran vacunados, por lo que es posible suponer que el convencimiento de los padres era fundamental para concretar el proceso. Lo más destacado de la observación por mes es que es posible identificar los meses de mayo, junio y julio como los de mayor cantidad de vacunados, situación que se explica desde las convocatorias de vacunación, porque en la época se relacionaban los meses de calor como los más propicios para el surgimiento de viruela natural. ${ }^{24}$

Por otra parte, sobre el total de vacunados en 1816 la falla de inmunización ${ }^{25}$ se situó en $10 \%$ (véase gráfica 3), lo que quiere decir que, de los 550 individuos vacunados, 60 tuvieron que vacunarse más de una vez porque no desarrollaron la reacción esperada. Este dato es destacado debido a que los factores que pudieron incidir en la falla de inmunización van desde una mala aplicación del fluido vacuno hasta que los individuos ya hubieran presentado viruela (de manera leve para no haberlo notado) o alguna variante de viruela bovina que los hubiera inmunizado anteriormente.

En contraste, 1817 presentó una disminución en la totalidad de individuos vacunados, no obstante, es necesario aclarar que para este año se cuenta con registros hasta el mes de octubre, por lo que es posible que con la información faltante se pudiera obtener un total de vacunaciones similar al de $1816{ }^{26}$ Así, el total para 1817 se situó en 433 individuos vacunados, de los cuales 329 fueron menores a doce meses y 104 mayores a un año (véase gráfica 4). El promedio de vacunados por mes fue de 43.3 individuos, aunque la distribución mensual de vacunados presenta rasgos distintos a la evidenciada en 1816, coinciden al presentar los meses más calurosos como los de mayor afluencia (véase gráfica 5). Sin embargo, al comparar ambas gráficas de vacunados por

con reserva estos datos, la información presentada en las vacunaciones mensuales (junto con la distribución por rango de edad) sobrepasa el promedio referido, por lo que es posible suponer que estas campañas no se limitaron a vacunar neonatos, sino que también alcanzaron a otros individuos. Los registros referidos se encuentran en expedientes dispersos reunidos en los siguientes volúmenes: Compilación de documentos relativos a la viruela, 1815-1817. Fondo Instituciones coloniales-historia. Vol. 530; y Compilación de documentos relativos a epidemias, 1815-1818. Fondo Real Hacienda-epidemias. Vol. 14, ambos en AGN, México.

${ }^{24}$ Por viruela natural se entendía aquella que se presentaba de manera espontánea y no por medio de inoculaciones.

${ }^{25}$ También conocido como fallo vacunal primario, se refiere a la falta de seroconversión inicial de la vacuna. Es decir, que no se presenten los anticuerpos esperados tras la aplicación.

${ }^{26}$ A través de un método de extrapolación mediante un modelo de regresión lineal simple, podrían obtenerse aproximados de los meses faltantes, sin embargo, para mantener intacta la información se trabaja únicamente con los datos presentes en la documentación. 
Gráfica 3. Falla de inmunización sobre el total de vacunados en 1816

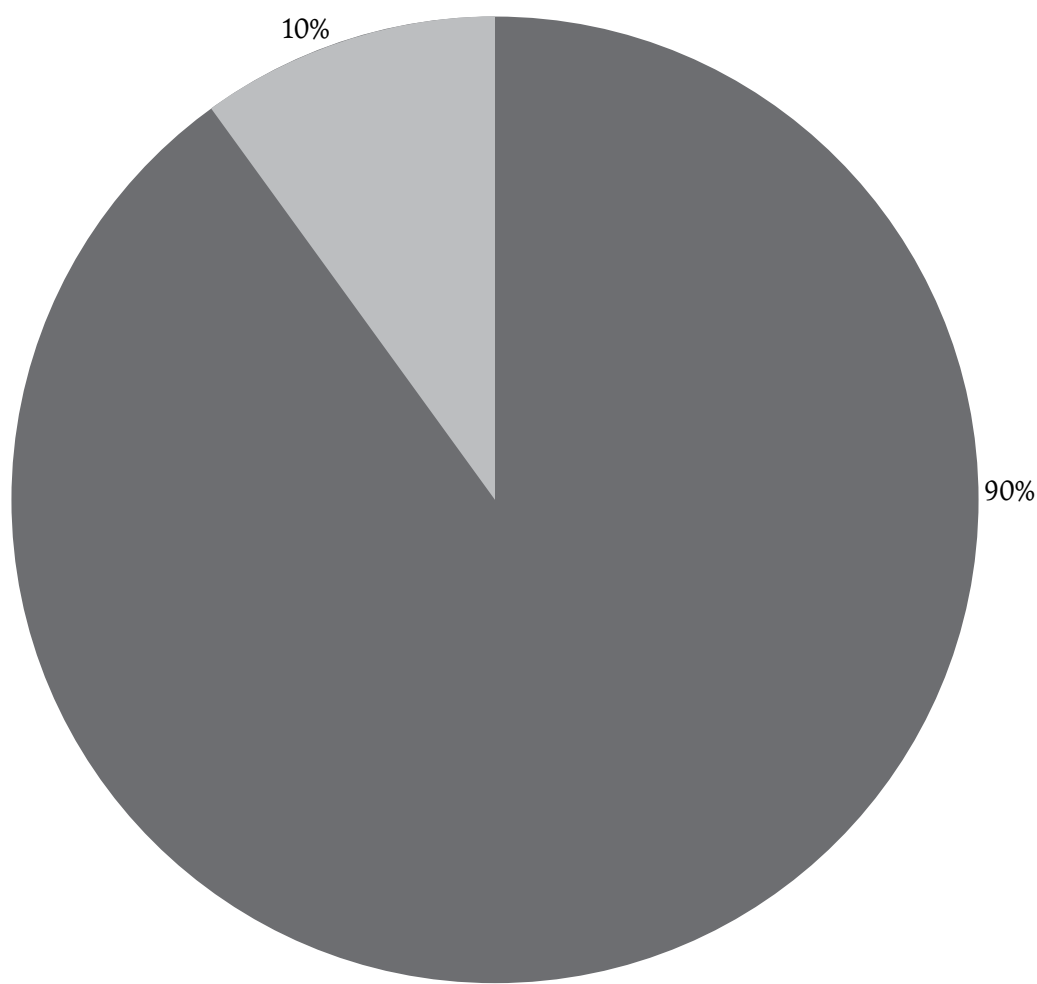

Total de vacunados

Falla de inmunización

Fuente: elaboración propia a partir de Compilación de documentos relativos a la viruela, 1815-1817. Fondo Instituciones coloniales-historia. Vol. 530; y Compilación de documentos relativos a epidemias, 1815-1818. Fondo Real Hacienda-epidemias. Vol. 14, ambos en AGN, México.

mes, octubre destaca por arrojar un repunte en la afluencia, lo que genera una incógnita que no es posible resolver a partir del resto de los documentos que acompañan los registros de vacunación.

Por otra parte, el porcentaje de falla de inmunización presentado en 1817 se situó en $12 \%$ (véase gráfica 6), lo que señala un aumento en comparación con el suscitado el año anterior, situación que defiende la hipótesis de 


\section{Gráfica 4. Vacunados en 1817, agrupados por rango de edad}

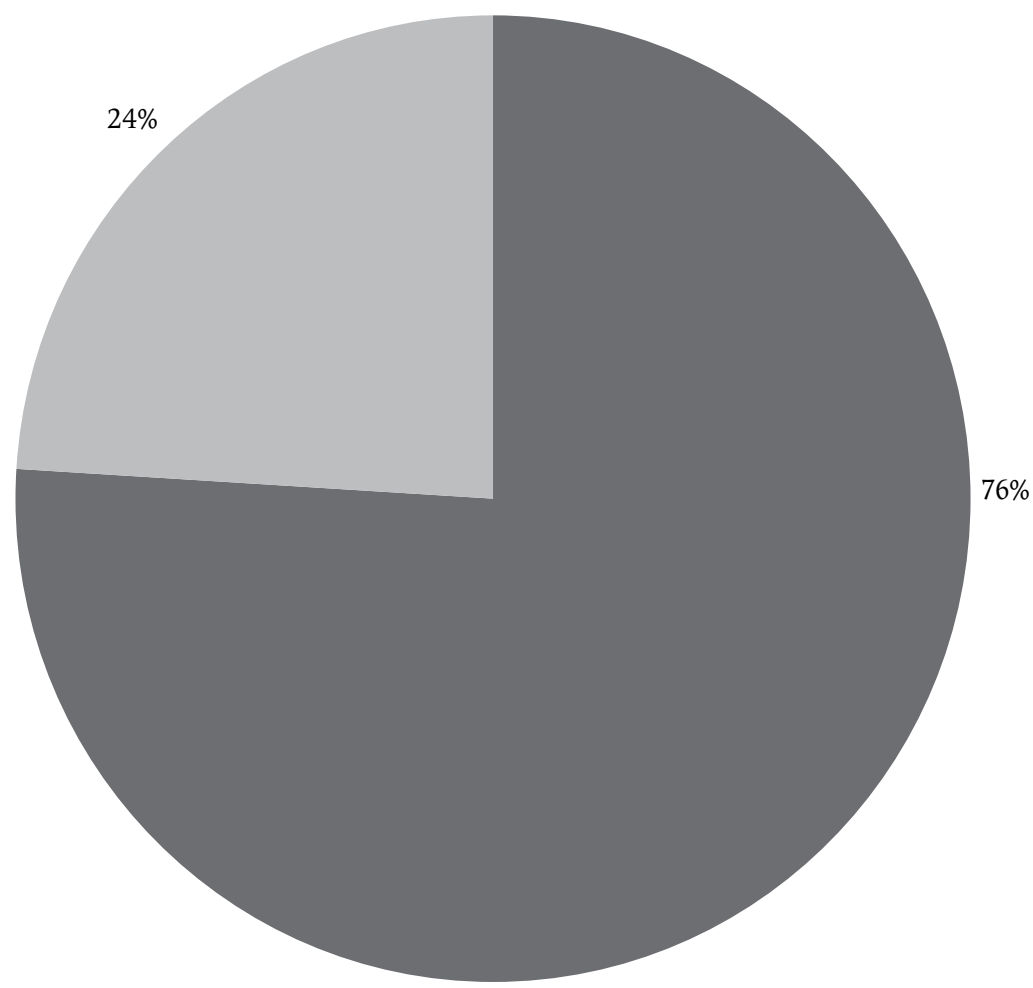

Total de vacunados hasta 12 meses

Total de vacunados más de 12 meses

Fuente: elaboración propia a partir de Compilación de documentos relativos a la viruela, 1815-1817. Fondo Instituciones coloniales-historia. Vol. 530; y Compilación de documentos relativos a epidemias, 1815-1818. Fondo Real Hacienda-epidemias. Vol. 14, ambos en AGN, México.

que el margen de error se debió a factores humanos y posibles inmunizaciones previas. En este sentido, es posible suponer que estos porcentajes en la falla de inmunización se deban a que el método era reciente y los desarrollos médicos estaban muy lejos de la sofisticación que presentaron las campañas masivas de vacunación propias del siglo xx. 


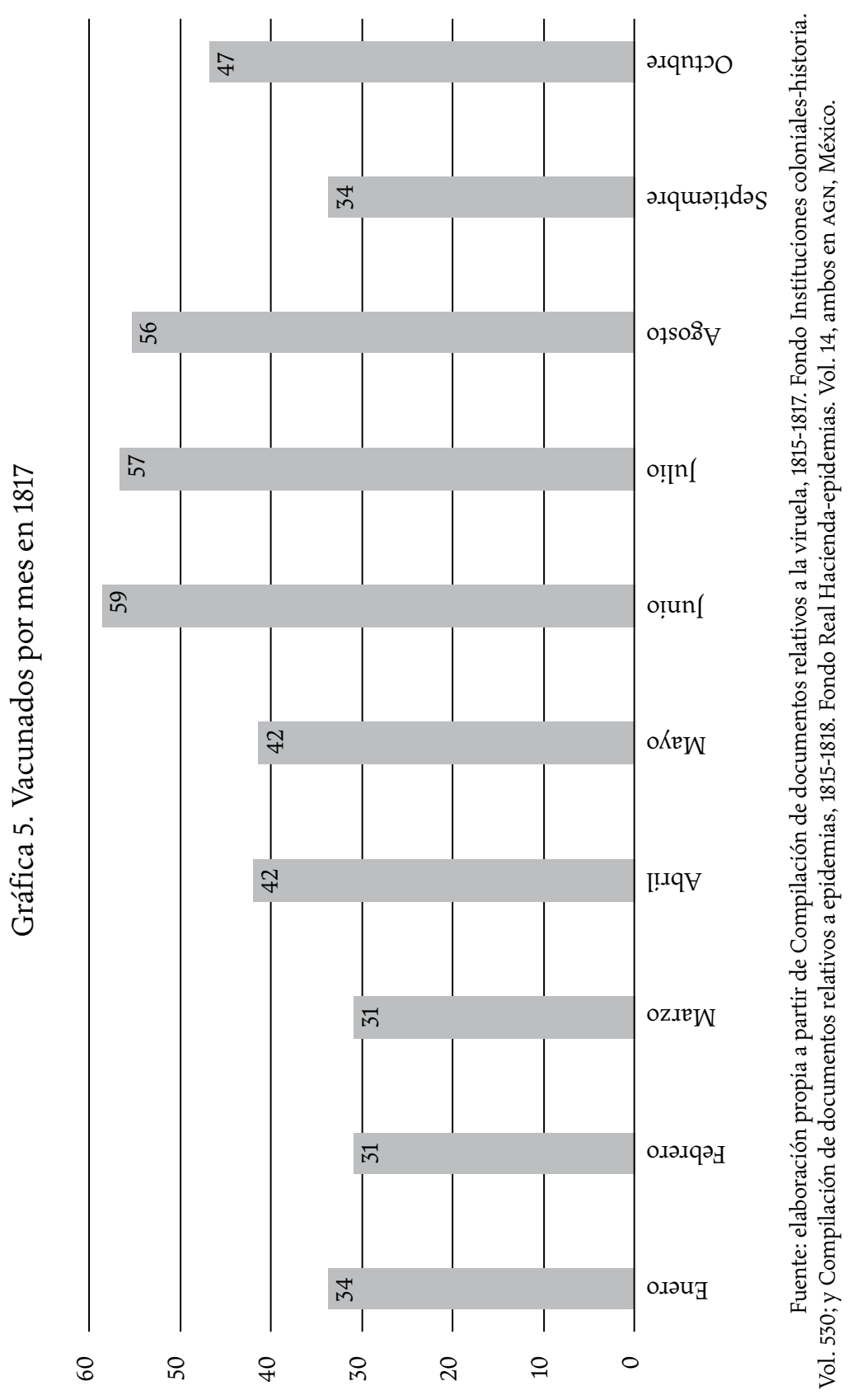


Gráfica 6. Falla de inmunización sobre el total de vacunados en 1817

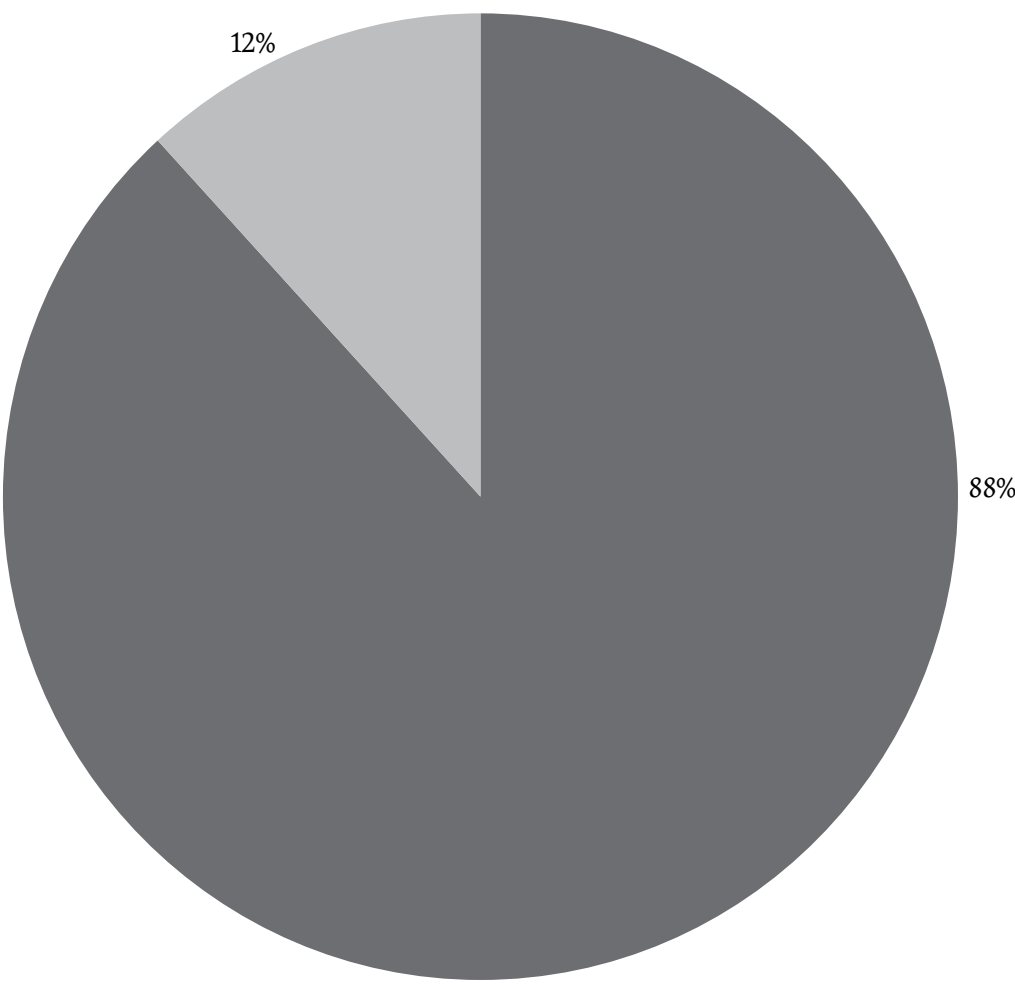

Total de vacunados

Falla de inmunización

Fuente: elaboración propia a partir de Compilación de documentos relativos a la viruela, 1815-1817. Fondo Instituciones coloniales-historia. Vol. 530; y Compilación de documentos relativos a epidemias, 1815-1818. Fondo Real Hacienda-epidemias. Vol. 14, ambos en AGN, México.

En síntesis, los resultados de la comisión de vacunación del bienio 18161817 se pueden agrupar en dos cuadros que reflejan el total de vacunados por año (cuadro 1), así como los vacunados que presentaron falla de inmunización sobre el total de vacunados por año (cuadro 2). Esto permite dimensionar de mejor manera el impacto que tuvo la aplicación de la vacuna en un periodo relativamente corto. 


\section{Cuadro 1. Total de vacunados en el Puerto de Veracruz durante el bienio 1816-1817}

$\begin{array}{cccc}\text { Vacunados hasta } & \text { Vacunados mayores } & \\ \text { Año } & \text { doce meses de edad } & \text { a doce meses de edad } & \text { Total de vacunados } \\ 1816 & 369 & 181 & 550 \\ 1817 & 329 & 104 & 433\end{array}$

Fuente: elaboración propia a partir de Compilación de documentos relativos a la viruela, 1815-1817. Fondo Instituciones coloniales-historia. Vol. 530; y Compilación de documentos relativos a epidemias, 1815-1818. Fondo Real Hacienda-epidemias. Vol. 14, ambos en AGN, México.

\section{Cuadro 2. Total de vacunados y falla de inmunización en el Puerto de Veracruz durante el bienio 1816-1817}

$\begin{array}{ccc}\text { Año } & \text { Total de vacunados } & \text { Falla de inmunización total } \\ 1816 & 550 & 60 \\ 1817 & 433 & 58\end{array}$

Fuente: elaboración propia a partir de Compilación de documentos relativos a la viruela, 1815-1817. Fondo Instituciones coloniales-historia. Vol. 530; y Compilación de documentos relativos a epidemias, 1815-1818. Fondo Real Hacienda-epidemias. Vol. 14, ambos en AGN, México.

Para entender el impacto que tuvieron estas comisiones de vacunación es necesario contextualizar la información presentada. Lamentablemente no existen registros precisos sobre la cantidad de habitantes en Veracruz durante el bienio que examina esta investigación; sin embargo, se cuenta con datos del año 1820, en el que se estima que en la ciudad de Veracruz había 11000 habitantes (INEGI, 1994, p. 38). Esta cifra puede servir como referente aproximado de la población en el bienio 1816-1817, por lo que, para efectos comparativos, se asumirá que en dichos años se contaba con los mismos 11000 habitantes que los estimados en $1820 .{ }^{27}$ Por lo tanto, en 1816 se vacunó a 5\% de la pobla-

${ }^{27}$ La razón de tomar la población de 1820 para el bienio que estudia esta investigación se fundamenta en que en el periodo 1810-1846 se estima que la tasa de crecimiento medio anual de 
ción total de la ciudad, mientras que en 1817 a 3.9\%. A simple vista estas cifras pueden resultar mínimas, sin embargo, hay que considerar un aspecto fundamental. Desde finales del siglo XVIII la zona había sido azotada por epidemias de viruela de manera recurrente, y tan sólo tres años antes del bienio aquí estudiado la región experimentó una epidemia que había entrado por el puerto. ${ }^{28}$ Por lo tanto, se puede suponer que los habitantes que sobrevivieron a la epidemia de 1813 no consideraban necesario vacunarse debido a que se sabía que aquel que se recuperaba de la enfermedad se volvía inmune de por vida.

Otro aspecto que pudo influir en que la campaña únicamente alcanzara a este porcentaje de la población, que en su mayoría se componía de menores de doce meses, es la manera en que se estructuraba el discurso de la convocatoria. A partir de la documentación de la comisión de vacunación es posible inferir que su principal objetivo era llegar a los nacidos por mes. Esta afirmación se fundamenta en que las autoridades de la campaña solicitaban los registros mensuales de bautizo a las parroquias de la ciudad, los anotaban en partidas específicas y se rescataban datos de los neonatos: nombre del infante, nombre de los padres (en caso de que tuviera ambos, si no únicamente se anotaba el nombre de la madre) y vivienda (calle y número). Posteriormente, en las actas de la campaña se anotaban los mismos datos de los individuos vacunados; de esta forma, al establecer un contraste entre ambos tipos de registros, es posible identificar que las autoridades situaron gran parte de las zonas de vacunación en calles donde hubiera un mayor número de nacidos. ${ }^{29}$ Además, los nombres de los niños en los registros de nacimiento también se encuentran en los registros de vacunados.

No obstante, la campaña no solamente estaba orientada a los neonatos de los que se tenía registro, también trató de llegar a prácticamente toda la población, pero específicamente a los infantes. ${ }^{30}$ Como se ha mencionado, la campaña de vacunación se movió por toda la ciudad, ya fuera estableciéndose

población fue de $0.373 \%$, por lo que, para efectos prácticos, la variación poblacional entre 18161817 y 1820 habría sido mínima (INEGI, 1994, p. 14).

${ }^{28}$ Véase el inicio de este trabajo, en el que se presenta el caso de la tripulación del navío Miño que desembarcó en el puerto en 1813 con el objetivo de introducir efectivos militares al territorio.

${ }^{29}$ Compilación de documentos relativos a la viruela, 1815-1817. Fondo Instituciones coloniales-historia. Vol. 530; y Compilación de documentos relativos a epidemias, 1815-1818. Fondo Real Hacienda-epidemias. Vol. 14, ambos en AGN, México.

${ }^{30}$ Aunque para la época resulta complicado determinar la edad en la que se concebía el cambio entre infancia y adultez, las campañas apelaban a que los padres llevaran a sus hijos, 
en casas o tiendas destinadas a vacunar por uno o dos días. La manera en que se exhortaba a la población a que se vacunara era mediante bandos colocados en las calles. Estos bandos apelaban a que los padres llevaran a sus hijos a las casas de vacunación, defendían las bondades del nuevo descubrimiento, enfatizaban que no había riesgos en su aplicación, que era gratuita debido a que el Ayuntamiento absorbía los costos, destacaban la brevedad del procedimiento y abonaban a la necesidad de la vacunación preguntando a los padres: “iseremos nosotros los verdugos de nuestros propios hijos?" ${ }^{11}$ Es precisamente la naturaleza de estos bandos, así como la estructura de la propia comisión, lo que arroja indicios sobre el inicio de una consciencia de prevención. En gran medida, esta investigación sostiene que la campaña estudiada es un claro ejemplo del desarrollo de una consciencia de prevención, en tanto que el propio diseño y desarrollo de las empresas de vacunación permiten identificar una planificación cuyo objetivo concreto era inmunizar al grupo de mayor riesgo ante una epidemia.

A reserva de lo que se ha presentado hasta este momento, el bienio 1816-1817 también ofrece algunas incógnitas respecto a estas primeras comisiones de vacunación. Es necesario enfatizar que la información utilizada en esta investigación refiere que existieron otras campañas esporádicas desde el año 1815, también se encontraron registros incompletos de vacunación para algunos meses del bienio, aunque de otras partes de la Intendencia de Veracruz. Sin embargo, una de las incógnitas más importantes es que también se encontraron registros incompletos procedentes de otras ciudades del virreinato, los cuales pueden ser indicadores de campañas existentes en distintas partes del territorio, pero que será necesario rastrear e investigar con mayor profundidad en trabajos posteriores. Sin embargo, es necesario aclarar que la lógica de la época no era la erradicación de la enfermedad, sino que se apeló a este nuevo método como una forma de anticipación a las epidemias. De esta forma podría explicarse la razón por la cual estas comisiones se establecían de manera esporádica y por qué el ímpetu mostrado por la población veracruzana de estos años no se mantuvo de manera constante durante el resto del siglo XIX (Cramaussel, 2008, pp. 101-132; Robichaux, 2010, pp. 21-40).

situación que indica que se trataba de menores que no se consideraban facultados para tomar decisiones independientes.

${ }^{31}$ Compilación de documentos relativos a la viruela, 1815-1817. Fondo Instituciones coloniales-historia. Vol. 530, exp. 4, f. 12. AGN, México. 


\section{CONSIDERACIONES FINALES}

Esta investigación ha presentado las particularidades de una comisión de vacunación en el puerto de Veracruz durante el bienio 1816-1817. De manera general, se logró evidenciar que el diseño y aplicación de la campaña es reflejo de una consciencia de prevención primigenia debido a que buscó proteger a un grupo poblacional tradicionalmente propenso a morir ante brotes de viruela. Además, la organización, ejecución y seguimiento de la campaña estuvieron enteramente coordinados por las autoridades del gobierno virreinal.

Otro aspecto que se ha destacado en esta investigación es que la población veracruzana recibió con entusiasmo la vacuna, un método totalmente nuevo para la época pero que rápidamente se adoptó como necesario para proteger a los infantes. En este sentido, la investigación también arrojó detalles importantes respecto a la dinámica de convocatoria, difusión y administración de las vacunas, donde resaltan los bandos que hacían pública la información para que las personas se acercaran a los diferentes puntos en los que se administraba el fluido vacuno. No obstante, también se destacó que en el bienio estudiado se presentó una alta tasa en la falla de inmunización, situación que sugiere que los facultativos encargados de administrar las dosis estaban en un proceso formativo que se reflejaba en aplicaciones insatisfactorias. Además, es necesario tener en cuenta que para la época los estándares de higiene eran distintos a los experimentados en la actualidad, por lo que es posible que el fluido vacuno se contaminara, que las agujas no fueran estériles o que simplemente no se dominara la técnica de aplicación.

Por último, está investigación se concentró en estudiar la viruela desde una perspectiva a la que la historiografía había prestado poca atención: desde la consciencia de prevención de las propias autoridades virreinales. De esta forma, el caso de las campañas de vacunación en un periodo tan complicado como el de la insurgencia novohispana da cuenta de que la propia guerra desató una serie de enfermedades que, además de las propias muertes por consecuencia de la guerra, diezmaron a la población. También da cuenta de la manera en que los nuevos descubrimientos médicos eran bien recibidos entre la sociedad novohispana, los intentos por establecer comisiones permanentes cuyo objetivo era prevenir epidemias de viruela y la manera en que la población atendió a estas convocatorias.

Así, esta investigación es apenas un aporte concreto de lo que considero se puede entender como el origen de una consciencia de prevención en 
la medicina del otrora virreinato de Nueva España sobre el que se erigió la nación mexicana. Sin embargo, es necesario contextualizar estos avances con los trabajos citados a lo largo de la investigación y entender que la lógica de la época apelaba al uso de la vacuna como una medida de anticipación a las epidemias, cuyo uso era más bien esporádico y que estaba lejos de acercarse a la consciencia de erradicación que se evidenció desde los años cuarenta del siglo xx. Así, es necesario tener presente que el bienio aquí estudiado es un momento extraordinario en la lógica de aplicación de la vacuna que distintos autores han señalado respecto al siglo xIX mexicano.

En consecuencia, futuros trabajos tendrán que orientarse a estudiar con más detalle el establecimiento, impacto y seguimiento de estas comisiones de vacunación, la manera en que funcionaron durante la insurgencia, la coordinación que ejercieron las autoridades virreinales, cómo se adaptaron tras la proclamación de la independencia y hasta qué punto se pueden establecer rupturas y continuidades con los proyectos de vacunación que surgieron a lo largo del siglo xIx. Todo ello con el objetivo de ampliar nuestro conocimiento sobre las primeras etapas de la profesionalización de la medicina mexicana que, indudablemente, tuvo sus orígenes en el periodo virreinal.

\section{LISTA DE REFERENCIAS}

Agostoni, C. (2016). Médicos, campañas y vacunas. La viruela y la cultura de su prevención en México. México: unAm/Instituto Mora.

Bustamante, M. (1982). La viruela en México, desde su origen hasta su erradicación. En E. Florescano y E. Malvido (coords.), Ensayos sobre la historia de las epidemias en México (pp. 67-92). México: Instituto Mexicano del Seguro Social.

Carrillo, A. M. (2010). Por voluntad o por fuerza: la lucha contra la viruela en el porfiriato. En C. Cramaussel y M. A. Magaña Mancillas (eds.), El impacto demográfico de la viruela en México de la época colonial al siglo xx. Vol. II: La viruela después de la introducción de la vacuna. Zamora: El Colegio de Michoacán.

Cramaussel, C. (2008). La lucha contra la viruela en Chihuahua durante el siglo XIX. Relaciones Estudios de Historia y Sociedad, 29(114), 101-132.

Cramaussel, C. (ed.) (2010). El impacto demográfico de la viruela en México de la época colonial al siglo xx. Vol. I: La viruela antes de la introducción de la vacuna. Zamora: El Colegio de Michoacán. 
Crosby, A. W. (1991). El intercambio transoceánico. Consecuencias biológicas y culturales a partir de 1492. México: Universidad Nacional Autónoma de México.

Díaz del Castillo, B. (1929). Historia verdadera de la conquista de laNueva España. Santa Barbara: Santa Barbara Mission.

Dimas Arenas, T. (2010). Las medidas de prevención contra la viruela en el siglo XIX y la epidemia de 1865-1866 en Sombrerete, Zacatecas. En C. Cramaussel y M. A. Magaña Mancillas (eds.) (2010), El impacto demográfico de la viruela en México de la época colonial al siglo xx. Vol. II: La viruela después de la introducción de la vacuna. Zamora: El Colegio de Michoacán.

Espinosa Cortés, L. y Miranda Ocampo, R. (2010). La epidemia de viruela de 17961798: de Teotitlán del Valle, Oax. a la ciudad de México. En C. Cramaussel (ed.), El impacto demográfico de la viruela en México de la época colonial al siglo xx. Vol. I: La viruela antes de la introducción de la vacuna (pp. 71-92). Zamora: El Colegio de Michoacán.

Fernández del Castillo, F. (1982). Don Francisco de Balmis y los resultados de su expedición vacunal a América. En E. Florescano y E. Malvido (coords.), Ensayos sobre la historia de las epidemias en México (pp. 329-337). México: Instituto Mexicano del Seguro Social.

Florescano, E. y Malvido, E. (comps.) (1982). Ensayos sobre la historia de las epidemias en México (2 vols.). México: Instituto Mexicano del Seguro Social.

Fournier, R. (1982). La viruela desde 1520 hasta la expedición de Balmis. En E. Florescano y E. Malvido (coords.), Ensayos sobra la historia de las epidemias en México (pp. 249-257). México: Instituto Mexicano del Seguro Social.

Galván Hernández, J. L. (2017). Al mejor servicio del rey. La Junta Superior de Real Hacienda de Nueva España 1786-1821. (Tesis de licenciatura inédita). Instituto de Investigaciones Dr. José María Luis Mora, México.

Gil, F. (1784). Disertación físico-médica en la cual se prescribe un método seguro para preservar a los pueblos de viruelas hasta lograr la completa extinción de ellas en todo el reino. Madrid: Don Joaquín Ibarra Impresor de Cámara de S. M.

Harrison, T. R. (2002). Principios de medicina interna. México: McGraw Hill.

Instituto Nacional de Estadística, Geografía e Informática [INEGI] (1994). Estadísticas históricas de México. Aguascalientes: Autor.

Jáuregui Frías, L. (1999). La Real Hacienda de Nueva España, su administración en la época de los intendentes 1786-1821. México: Facultad de Economía-unAM.

Jenner, E. (1798). An inquiry into the causes and effects of the variolæ vaccince. A disease discovered in some of the western counties of England particulary Gloucestershire and known by the name of The Cow Pox. Londres: Sampson Low. 
Jenner, E. (1799). Further observations on the variolæ vaccinae or cow pox. Londres: Sampson Low.

Kotar, S. L. y Gressler, J. E. (2013). Smallpox. A history. Norte de Carolina: McFarland y Company, Inc. Publishers.

Kuethe, A. y Andrien, K. J. (2014). The spanish atlantic world in the eighteenth century: War and the Bourbon reforms, 1713-1796. Nueva York: Cambridge University Press.

Méndez Main, S. M. (2010). Epidemias y medidas de prevención en Veracruz, 17971895. En C. Cramaussel (ed.), El impacto demográfico de la viruela en México de la época colonial al siglo xx. Vol. III: Estudios de larga duración (pp. 81-98). Zamora: El Colegio de Michoacán.

Molina del Villar, A., Márquez Morfín, L. y Pardo Hernández, C. (eds.) (2013). El miedo a morir. Endemias, epidemias y pandemias en México: análisis de larga duración. México: Centro de Investigaciones y Estudios Superiores en Antropología Social/ Instituto Mora/Benemérita Universidad Autónoma de Puebla.

Moreau de la Sarthe, J. L. (1803). Tratado histórico y práctico de la vacuna: que contiene en compendio el origen y los resultados de las observaciones y experimentos sobre la vacuna, con un examen imparcial de sus ventajas, y de las objeciones que se le han puesto, con todo lo demás que concierne a la práctica del nuevo modo de inocular. Madrid: Imprenta Real.

Ortiz Escamilla, J. (2014). Guerra y gobierno. Los pueblos y la independencia de México, 1808-1825. México: El Colegio de México/Instituto Mora.

Ortiz Escamilla, J. (2017). Calleja. Guerra, botín y fortuna. Xalapa: Universidad Veracruzana/El Colegio de Michoacán.

Pardo Hernández, C. (2013). La primera expedición de la vacuna de Balmis en la ciudad de México, 1804. ¿Un combate contra la viruela o un debate de egos? En A. Molina del Villar, L. Márquez Morfín y C. Pardo Hernández (eds.), El miedo a morir. Endemias, epidemias y pandemias en México: análisis de larga duración (pp. 451462). México: Centro de Investigaciones y Estudios Superiores de Antropología Social/Instituto Mora/Benemérita Universidad Autónoma de Puebla.

Pietschmann, H. (2018). Las múltiples dimensiones históricas de las reformas fiscales en Nueva España del siglo xviII. En M. Bertrand y Z. Moutoukias, Cambio institucional y fiscalidad: mundo hispánico, 1760-1850. Madrid: Casa de Velázquez. Recuperado de https://dialnet.unirioja.es/servlet/libro?codigo=742352

Ramírez Martín, S. M. (2002). La salud del imperio: la Real Expedición Filantrópica de la vacuna. Madrid: Ediciones Doce Calles.

Robichaux, D. (2010). El papel de la viruela en la historia demográfica de México. Reflexiones a partir de cuatro siglos de "viruelas" en dos parroquias de Tlaxcala. En C. Cramaussel (ed.), El impacto demográfico de la viruela en México de la época co- 
lonial al siglo xx. Vol. III: Estudios de larga duración (pp. 21-40). Zamora: El Colegio de Michoacán.

Sánchez Santiró, E. (2013). Corte de Caja. La Real Hacienda de Nueva España y el primer reformismo fiscal de los Borbones (1720-1755). Alcances y contradicciones. México: Instituto Mora.

Sánchez Santiró, E. (2016). La imperiosa necesidad. Crisis y colapso del Erario de Nueva España (1808-1821). México: Instituto Mora/El Colegio de Michoacán.

Sánchez Uriarte, M. del C. (2013). Entre la salud pública y la salvaguarda del reino. Las fiebres misteriosas de 1813 y la guerra de Independencia en la Intendencia de México. En A. Molina del Villar, L. Márquez Morfín y C. Pardo Hernández, El miedo a morir. Endemias, epidemias y pandemias en México: análisis de larga duración (pp. 51-74). México: Centro de Investigaciones y Estudios Superiores de Antropología Social/Instituto Mora/Benemérita Universidad Autónoma de Puebla.

Torres Franco, C. P. y Cramaussel, C. (2017). Epidemias de sarampión en Nueva España y México (siglos XVII-Xx). Zamora: El Colegio de Michoacán.

Torres Sánchez, R. (2018). Tejiendo una Hacienda imperial. "Unir los manejos de la Real Hacienda de España y América” en el reinado de Carlos III. En M. Bertrand y Z. Moutoukias, Cambio institucional y fiscalidad: mundo hispánico, 1760-1850. Madrid: Casa de Velázquez. Recuperado de https://dialnet.unirioja.es/servlet/ libro?codigo $=742352$

Trejo Moreno, J. (2016). La epidemia de viruela de 1797 en el sagrario de la ciudad de México, vista a través de los registros parroquiales de defunción. (Tesis de maestría inédita). Instituto de Investigaciones Dr. José María Luis Mora, México.

Tuells, J. (2012). El proceso de revisión a la traducción de Francisco Xavier de Balmis del Tratado histórico y práctico de la vacuna de Moreau de la Sarthe. Gaceta Sanitaria. 26(4), 372-375.

Valdés Aguilar, R. (2010). La viruela desde el punto de vista médico. En C. Cramaussel (ed.), El impacto demográfico de la viruela en México de la época colonial al siglo Xx. Vol. I: La viruela antes de la introducción de la vacuna (pp. 27-36). Zamora: El Colegio de Michoacán.

Van Young, E. (2006). La otra rebelión. La lucha por la independencia de México, 18101821. México: FCE.

Veiga de Cabo, J., Fuente Díez, E. de la y Martín Rodero, H. (2007). La real Expedición filantrópica de la vacuna (1803-1810). Medicina y Seguridad del Trabajo, 53(209), 72-84.

Williamson, S. (2007). The vaccination controversy. The rise, reign and fall of compulsory vaccination for smallpox. Liverpool: Liverpool University Press. 


\section{OTRAS FUENTES}

AgN Archivo General de la Nación. México. 